\title{
Differences in breast-feeding initiation and continuation by maternal diabetes status
}

\author{
Reena Oza-Frank ${ }^{1, *}$, Ilana Chertok ${ }^{2}$ and Adam Bartley ${ }^{3}$
}

${ }^{1}$ Center for Perinatal Research, Research Institute at Nationwide Children's Hospital, Department of Pediatrics, The Ohio State University, 700 Children's Drive, Research Building 3, Columbus, OH 43205, USA: ${ }^{2}$ School of Nursing, West Virginia University, Morgantown, WV, USA: ${ }^{3}$ College of Public Health, The Ohio State University, Columbus, $\mathrm{OH}$, USA

Submitted 1 0ctober 2013: Final revision received 5 March 2014: Accepted 3 April 2014: First published online 8 May 2014

\begin{abstract}
Objective: To examine (i) the prevalence of and associations between breastfeeding initiation and continuation by maternal diabetes status and (ii) the reasons for not initiating and/or continuing breast-feeding by maternal diabetes status.

Design: Secondary data analyses of a population-based cross-sectional study were conducting using data from the US Centers for Disease Control and Prevention's Pregnancy Risk Assessment Monitoring System (PRAMS), 2009-2011. Multivariable logistic regression was used to investigate the associations between breast-feeding initiation and continuation by diabetes status.

Setting: Thirty states and New York City, USA.

Subjects: Mothers of recently live-born infants, selected by birth certificate sampling.

Results: Among 72755 women, 8.8\% had gestational diabetes mellitus (GDM) and $1.7 \%$ had pregestational diabetes mellitus (PDM). Breast-feeding initiation was similar among GDM and no diabetes mellitus (NDM) women (80.8\% $v$. $82.2 \%$, respectively, $P=0 \cdot 2)$, but continuation was lower among GDM $(65 \cdot 7 \% v$. $68.8 \%$, respectively, $P=0 \cdot 01)$. PDM women had lower initiation and continuation compared with NDM $(78.2 \%, P=0.03$ and $60.4 \%, P<0.01$, respectively). In adjusted analyses, current smoking status was a significant effect modifier for initiation, but not for continuation.

Conclusions: Differences in breast-feeding initiation and continuation prevalence by maternal diabetes status may reflect differences in prenatal education, indicating the need for increased efforts among PDM women. Additionally, nonsmoking women with PDM or GDM would benefit from additional breast-feeding education.
\end{abstract}

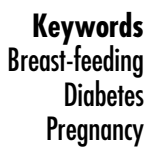

The prevalence of diabetes in pregnancy in the USA ranges from $1 \%$ to $14 \%$, depending on various factors including population, ethnicity, maternal age, BMI, socio-economic status, screening method and diagnostic definition of diabetes $^{(1,2)}$. The American Diabetes Association suggests that women who screen positive for diabetes before or during their initial prenatal visit be considered as having pregestational diabetes mellitus (PDM), thereby impacting treatment during and following pregnancy ${ }^{(2)}$. Additionally, it recommends that women with glucose intolerance, excluding overt diabetes, with onset in or first recognized in pregnancy be classified as having gestational diabetes mellitus (GDM). Research has shown that the prevalence of both PDM (type 1 and type 2 diabetes) and GDM has been increasing over time in the $\mathrm{USA}^{(3-6)}$.

Maternal diabetes in pregnancy may cause 'metabolic imprinting' and result in metabolic dysregulation in infants ${ }^{(7)}$, increasing the risk of the development of neonatal hypoglycaemia in early life and type 2 diabetes, obesity and metabolic syndrome later in life ${ }^{(8-12)}$. Diabetes in pregnancy increases the risk of premature birth, as well as increases the risk for infant morbidity and mortality ${ }^{(13,14)}$.

Breast-feeding is a modifiable health behaviour that is health promotional as it augments infant immunoprotection and nurtures growth and development ${ }^{(15)}$. Lack of breastfeeding is associated with infants' later risk of developing type 1 diabetes ${ }^{(16)}$ and type 2 diabetes ${ }^{(17)}$. Early breastfeeding has been associated with improved glycaemic outcomes in infants born to women with diabetes in pregnancy ${ }^{(18,19)}$. On the maternal side, lack of breast-feeding is associated with developing type 2 diabetes ${ }^{(20)}$, with a dosedependent effect for longer duration and higher intensity associated with lower risk of postpartum diabetes among women with GDM history ${ }^{(21-26)}$. 
Yet, there are few data on differences in breast-feeding initiation and continuation by diabetes status in the USA. A recent Canadian study found that the prevalence of breast-feeding at hospital discharge among women with any type of diabetes was lower than in women without diabetes (NDM) and a higher prevalence of breast-feeding initiation was noted among women with GDM compared with those with $\mathrm{PDM}^{(27)}$. Studies conducted in Germany also found lower prevalence of breast-feeding initiation and duration among women with type 1 diabetes compared with $\mathrm{NDM}^{(28,29)}$ and among women with PDM compared with GDM, likely due to various reasons ${ }^{(30)}$. For example, compared with NDM, women with type 1 diabetes experienced more birth-related complications such as emergency caesarean delivery, neonatal hypoglycaemia, and interventions such as oral formula supplementation and intravenous glucose administration, which may contribute to the lower prevalence of breast-feeding by hospital discharge ${ }^{(31)}$.

There is also a dearth of information published on reasons for breast-feeding initiation and continuation among women with diabetes in the USA. In a study conducted in the UK, in answer to an open-ended question regarding breast-feeding cessation among women with PDM and GDM, the most common reason for termination was perceived insufficient milk supply ${ }^{(32)}$, although it was not validated by measurement. The perception of delayed lactogenesis II or milk production insufficiency has been found among women with PDM and $\mathrm{GDM}^{(33-36)}$. Formula supplementation may be used when women feel that breast-feeding does not satisfy their infants, which may contribute to further reduction in milk production and less reliance on and confidence in breast-feeding, thereby resulting in shortened duration ${ }^{(37-39)}$.

As the prevalence of diabetes in the USA increases ${ }^{(5)}$, there is a greater need to address lactation among women with diabetes during pregnancy. The purpose of the present study was to examine (i) the prevalence of and associations between breast-feeding initiation and continuation by maternal diabetes status and (ii) the reasons for not initiating and/or continuing breast-feeding by maternal diabetes status.

\section{Methods}

Secondary data analyses were conducted using data from the Pregnancy Risk Assessment Monitoring System (PRAMS), 2009-2011. PRAMS is administered by the Centers for Disease Control and Prevention in collaboration with participating state health departments in thirty-seven states (plus New York City and the Yankton Sioux Tribe in South Dakota). PRAMS methods have been documented in detail previously ${ }^{(40-43)}$. Briefly, each month, a stratified random sample of 100 to 300 women with recent live births is selected from the infant birth certificates from each state. A self-administered questionnaire is mailed to each eligible mother at 2 to 4 months postpartum. Data are weighted to adjust for survey design, non-coverage and non-response. Surveys from 2009 to 2011 in thirty states and New York City were included in the current analyses.

The PRAMS questionnaire consists of core questions that appear on all participating state surveys, standard questions that states may select, and state-developed questions tailored to individual states. In 2009-2011, the core questions on self-reported diabetes were modified to better differentiate the pre-pregnancy and gestational diabetes. Self-reported gestational diabetes was obtained by the response to the question, 'During your most recent pregnancy, were you told by a doctor, nurse, or other health care worker that you had gestational diabetes (diabetes that started during this pregnancy)?' Self-reported pre-pregnancy diabetes was based on responses to the question, 'Before you got pregnant with your new baby, were you ever told by a doctor, nurse, or other health care worker that you had type 1 or type 2 diabetes (this is not the same as gestational diabetes or diabetes that starts during pregnancy)?' Breast-feeding initiation was determined based on yes/no responses to the question, 'Did you ever breast-feed or pump breast milk to feed your new baby after delivery, even for a short period of time?' Women who answered 'yes' to the initiation question were asked about breast-feeding continuation, 'How many weeks or months did you breast-feed or pump milk to feed your baby?' Breast-feeding continuation was defined as breast-feeding for at least 2 months, as this time point has previously been used to define breast-feeding continuation $^{(31)}$ and reflects the minimum amount of time after delivery that the survey is administered.

Women reporting both PDM and GDM were not counted as having either diabetes type and were excluded from analyses $(n 425)^{(44)}$. Additionally, women who answered 'no' to one of the diabetes questions and had data missing on the other diabetes question were excluded from the analyses ( $n$ 360). Finally, analyses were restricted to singleton births.

Bivariate associations between diabetes status and the following variables were tested: maternal age ( $\leq 19$ years, 20-24 years, 25-29 years, 30-34 years, $\geq 35$ years); race/ ethnicity (non-Hispanic White, non-Hispanic Black, Asian, Hispanic, Other); marital status; pre-pregnancy BMI (underweight, $\mathrm{BMI}<18.5 \mathrm{~kg} / \mathrm{m}^{2}$; normal weight, $\mathrm{BMI}=18.5-24.9$ $\mathrm{kg} / \mathrm{m}^{2}$; overweight, BMI $=25 \cdot 0-29 \cdot 9 \mathrm{~kg} / \mathrm{m}^{2}$; obese, BMI $\geq$ $30 \cdot 0 \mathrm{~kg} / \mathrm{m}^{2}$ ); maternal level of education (<high school, high school, >high school); previous live births; preterm birth (gestational age $<37$ weeks); intention to become pregnant; current smoking status; participation in the Special Supplemental Nutrition Program for Women, Infants, and Children (which provides nutrition education, breast-feeding education and support; supplemental, highly nutritious foods; and referral to prenatal and paediatric health care and other maternal and child health and human service programmes to income-eligible women); insurance at delivery (Medicaid, other; Medicaid is a human service programme intended to provide income-eligible individuals with health insurance); 
income (<\$US 25000, \$US 25000-34999, \$US 3500049999, $\geq \$$ US 50000); infant admission to the neonatal intensive care unit; type of delivery (vaginal, caesarean section); adequacy of prenatal care determined by calculating the Kotelchuck index ${ }^{(45)}$ (a composite score summarizing prenatal care based on the number and timing of prenatal visits); and whether or not breast-feeding was discussed with health-care workers during prenatal care.

Multivariable logistic regression models were built to investigate the associations between breast-feeding initiation and continuation by diabetes status, adjusting for the sixteen potential confounders. Main effects for the multivariable models were chosen using two steps. First, all variables were tested simultaneously, removing variables that were not significant $(P>0.05)$ one at a time with diabetes status modelled as an indicator variable. Second, logistic regression models with all variables were built for each diabetes type as the exposure, separately. If a variable that had previously been removed was significant for at least one diabetes group, it was added back into the main effects model.

Once the main effects were chosen, interactions were examined. Interactions were considered significant at $P<0 \cdot 01$. An interaction between diabetes and smoking was tested because previous research has shown smoking to be associated with lack of breast-feeding initiation among $\mathrm{PDM}^{(18)}$. We found this interaction was significant in the breast-feeding initiation model $(P=0 \cdot 0008)$. Significant interactions between other main effects were present but upon further examination, did not meaningfully change the main effects odds ratios and thus were not included in the final model. In the breast-feeding continuation model there were significant interactions present but none that meaningfully changed the main effects odds ratios. As a result no interactions were included in the final continuation model.

The questions regarding reasons for not initiating/not continuing breast-feeding were standard questions voluntarily selected by states for inclusion on the questionnaire. Eight states included the question, 'What were your reasons for not breast-feeding your new baby?' All women who did not initiate breast-feeding were included in the analysis of this question. Eleven states and New York City included the question, "What were your reasons for stopping breastfeeding?' All women who initiated breast-feeding were included in the analysis of this question. For both questions, women were asked to check all the reasons that applied for not initiating/not continuing breast-feeding.

Statistical analyses were completed using survey procedures in the SAS statistical software package version 9.3. Nationwide Children's Hospital's Institutional Review Board deemed the study as non-human subjects research.

\section{Results}

The PRAMS data set contained 72755 observations from thirty states and New York City during 2009-2011, representing a weighted frequency of 3756943 women. Among this national sample of pregnant women, $8.8 \%$ had GDM and $1.7 \%$ had PDM (Table 1). Breast-feeding initiation was similar between GDM and NDM (80.8\% v. $82.2 \%, P=0.2)$ but continuation was lower among GDM (65.7\% v. 68.8\%, $P=0.01$; Fig. 1). Initiation (78.2 \%, $P=0.03)$ and continuation $(60.4 \%, P<0.01)$ prevalence was consistently lower among PDM compared with NDM. Prevalence of initiation $(P=0 \cdot 2)$ and continuation $(P=0 \cdot 06)$ among GDM compared with PDM was similar.

A significant interaction between current smoking and diabetes was found for the breast-feeding initiation model, resulting in stratified analyses. Non-smokers had higher breast-feeding initiation prevalence compared with smokers, regardless of diabetes status. Specifically, among non-smokers, NDM had the highest breast-feeding initiation prevalence $(85.8 \%)$, followed by GDM (82.9\%) and PDM (80.4\%; data not shown). This was confirmed in stratified, adjusted models where, among non-smokers, those with PDM (OR $=0.71 ; 95 \%$ CI $0.54,0.94)$ and GDM $(\mathrm{OR}=0.83 ; 95 \% \mathrm{CI} 0.72,0.97)$ were significantly less likely to initiate breast-feeding compared with NDM (Table 2). However, among smokers, women with GDM had the highest breast-feeding initiation prevalence (70.0\%) compared with PDM (67.5\%) and NDM (64.0\%; data not shown). In adjusted models, among smokers, there were no differences in breast-feeding initiation between PDM and NDM (OR $=1.26 ; 95 \%$ CI $0.83,1.93)$ and those with GDM were more likely to initiate breast-feeding compared with NDM (OR $=1.31 ; 95 \%$ CI 1.03, 1.65; Table 2). There were no differences in breast-feeding initiation between GDM and PDM, regardless of smoking status.

For breast-feeding continuation at 2 months postpartum, women with PDM were significantly less likely to be breast-feeding compared with NDM (OR $=0.71 ; 95 \% \mathrm{CI}$ $0.56,0.91$; Table 2). There were no differences in breastfeeding continuation at 2 months between women with GDM and NDM (OR =0.89; $95 \%$ CI 0.79, 1.00) nor were there differences between women with GDM and PDM (OR $=1.25$; $95 \%$ CI 0.96, 1.63).

The question regarding reasons for not initiating breastfeeding included 3914 women and the question on not continuing breast-feeding included 10043 women. Among GDM and NDM, the three most common reasons for not initiating breast-feeding were: 'I didn't want to' (47.1\% and $47.7 \%$, respectively), 'I didn't like breast-feeding' (30.6\% and $28.9 \%$, respectively) and 'I had other children to take care of' (28.3\% and $20 \cdot 1 \%$, respectively; Table 3 ). Although two of the most common reasons were similar for PDM ( $52.5 \%$ for 'I didn't want to' and 35.4\% for 'I didn't like breast-feeding'), the third most common response among PDM was 'I was sick or on medicine' (29.9\%). The three most common reasons for not continuing breast-feeding were similar among GDM, NDM and PDM: 'I thought I was not producing enough milk' (27.6\%, 26.8\% and 24.8\%, respectively), 'Breast milk 
Table 1 Demographic characteristics of women by maternal diabetes status; Pregnancy Risk Assessment Monitoring System (PRAMS), 2009-2011

\begin{tabular}{|c|c|c|c|c|c|c|}
\hline & \multicolumn{2}{|c|}{ NDM ( $n$ 64 702) } & \multicolumn{2}{|c|}{ PDM (n 1401) } & \multicolumn{2}{|c|}{ GDM ( $n$ 6652) } \\
\hline & $\%$ & SE & $\%$ & SE & $\%$ & SE \\
\hline Whole sample ( $n$ 72 755) & 89.5 & 0.2 & 1.7 & 0.1 & $8 \cdot 8$ & 0.2 \\
\hline \multicolumn{7}{|l|}{$\mathrm{Age}^{\star \star \star}$} \\
\hline$\leq 19$ years & $8 \cdot 3$ & $0 \cdot 2$ & 8.7 & 1.5 & 4.6 & 0.5 \\
\hline $20-24$ years & 23.5 & 0.3 & $17 \cdot 8$ & 1.7 & 14.9 & 0.8 \\
\hline $25-29$ years & $30 \cdot 2$ & 0.3 & $28 \cdot 0$ & $2 \cdot 1$ & $27 \cdot 3$ & 1.0 \\
\hline 30-34 years & $25 \cdot 0$ & 0.3 & $23 \cdot 6$ & 1.9 & 29.8 & $1 \cdot 0$ \\
\hline$\geq 35$ years & $13 \cdot 0$ & 0.2 & $22 \cdot 0$ & 1.9 & $23 \cdot 3$ & 1.0 \\
\hline \multicolumn{7}{|l|}{ Race $^{\star \star \star}$} \\
\hline Non-Hispanic White & 63 & 0.2 & $65 \cdot 2$ & $2 \cdot 2$ & $50 \cdot 3$ & $1 \cdot 1$ \\
\hline Non-Hispanic Black & $11 \cdot 8$ & 0.2 & $13 \cdot 3$ & 1.4 & $13 \cdot 0$ & 0.7 \\
\hline Asian & 4.1 & $0 \cdot 1$ & 4.2 & 0.8 & 8.3 & 0.5 \\
\hline Hispanic & $17 \cdot 2$ & 0.2 & $14 \cdot 8$ & 1.9 & $24 \cdot 4$ & $1 \cdot 1$ \\
\hline Other & $3 \cdot 3$ & $0 \cdot 1$ & 2.5 & 0.4 & 4.0 & 0.4 \\
\hline \multicolumn{7}{|l|}{ Education level ${ }^{\star \star \star}$} \\
\hline$<$ High school & $13 \cdot 7$ & 0.3 & $13 \cdot 5$ & 1.7 & $18 \cdot 8$ & $1 \cdot 0$ \\
\hline High school & $25 \cdot 5$ & 0.3 & 24.8 & $2 \cdot 0$ & $26 \cdot 6$ & 1.0 \\
\hline >High school & $60 \cdot 9$ & 0.3 & $61 \cdot 7$ & $2 \cdot 3$ & $54 \cdot 6$ & $1 \cdot 1$ \\
\hline \multicolumn{7}{|l|}{ Income $e^{\star \star \star}$} \\
\hline$<\$$ US 25000 & $41 \cdot 8$ & 0.3 & 43.8 & $2 \cdot 3$ & $47 \cdot 0$ & $1 \cdot 1$ \\
\hline \$US $25000-34999$ & $9 \cdot 8$ & 0.2 & $7 \cdot 8$ & $1 \cdot 1$ & 11.4 & 0.7 \\
\hline \$US 35000-49 999 & $10 \cdot 6$ & 0.2 & $10 \cdot 6$ & 1.3 & $10 \cdot 8$ & 0.7 \\
\hline$\geq \$$ US 50000 & $37 \cdot 8$ & 0.3 & $37 \cdot 8$ & $2 \cdot 3$ & $30 \cdot 9$ & 1.0 \\
\hline Married & 63.1 & 0.3 & $62 \cdot 5$ & $2 \cdot 3$ & 61.5 & 1.1 \\
\hline \multicolumn{7}{|l|}{ Insurance at delivery** } \\
\hline Medicaid & $16 \cdot 2$ & $0 \cdot 2$ & 18.9 & $1 \cdot 8$ & $17 \cdot 7$ & 0.8 \\
\hline Other insurance & 83.8 & $0 \cdot 2$ & $81 \cdot 1$ & $1 \cdot 8$ & $82 \cdot 3$ & 0.8 \\
\hline Participation in WIC ${ }^{\star \star \star}$ & 43.9 & 0.3 & 43.7 & $2 \cdot 3$ & $52 \cdot 1$ & $1 \cdot 1$ \\
\hline \multicolumn{7}{|l|}{ Pre-pregnancy BMI $\left(\mathrm{kg} / \mathrm{m}^{2}\right)^{\star \star \star}$} \\
\hline Underweight $(<18.5)$ & 4.4 & $0 \cdot 1$ & $2 \cdot 7$ & 0.7 & $2 \cdot 9$ & 0.3 \\
\hline Normal (18.5-24.9) & 51.9 & 0.3 & $39 \cdot 3$ & $2 \cdot 3$ & 33.4 & $1 \cdot 1$ \\
\hline Overweight (25.0-29.0) & 23.8 & 0.3 & $24 \cdot 3$ & $2 \cdot 0$ & $26 \cdot 5$ & $1 \cdot 0$ \\
\hline Obese $(\geq 30.0)$ & $19 \cdot 8$ & 0.3 & 33.6 & $2 \cdot 2$ & $37 \cdot 2$ & $1 \cdot 1$ \\
\hline \multicolumn{7}{|l|}{ Parity ${ }^{\star * *}$} \\
\hline No previous birth & $42 \cdot 0$ & 0.3 & $40 \cdot 2$ & $2 \cdot 3$ & 34.9 & $1 \cdot 1$ \\
\hline Previous birth & $58 \cdot 0$ & 0.3 & $59 \cdot 8$ & $2 \cdot 3$ & $65 \cdot 1$ & $1 \cdot 1$ \\
\hline Preterm birth*** & $7 \cdot 0$ & $0 \cdot 1$ & $13 \cdot 9$ & 1.4 & $10 \cdot 3$ & 0.6 \\
\hline Intended to get pregnant & $48 \cdot 7$ & 0.3 & $47 \cdot 0$ & $2 \cdot 0$ & $48 \cdot 4$ & 1.0 \\
\hline Current smoker & $16 \cdot 8$ & 0.2 & $16 \cdot 7$ & 1.7 & $16 \cdot 3$ & 0.8 \\
\hline Admission to $\mathrm{NICU}^{\star \star \star}$ & $10 \cdot 2$ & 0.2 & $20 \cdot 3$ & 1.7 & $14 \cdot 8$ & 0.8 \\
\hline Adequate prenatal care ${ }^{\star}$ & 74.4 & 0.3 & $77 \cdot 5$ & $2 \cdot 1$ & $76 \cdot 9$ & 1.0 \\
\hline \multicolumn{7}{|l|}{ Delivery type } \\
\hline Caesarean section & $29 \cdot 8$ & 0.3 & $45 \cdot 7$ & $2 \cdot 3$ & $39 \cdot 4$ & $1 \cdot 1$ \\
\hline Vaginal & $70 \cdot 2$ & 0.3 & $54 \cdot 3$ & $2 \cdot 3$ & $60 \cdot 6$ & $1 \cdot 1$ \\
\hline Discussed breast-feeding with a health-care worker during any prenatal visit** & $82 \cdot 0$ & 0.3 & 84.6 & 1.6 & $83 \cdot 1$ & 0.9 \\
\hline \multicolumn{7}{|l|}{ Days after delivery questionnaire completed } \\
\hline Mean & \multicolumn{2}{|c|}{$116 \cdot 7$} & \multicolumn{2}{|c|}{$115 \cdot 0$} & \multicolumn{2}{|c|}{$118 \cdot 2$} \\
\hline Median & \multirow{2}{*}{\multicolumn{2}{|c|}{$\begin{array}{c}107 \\
241(61-302)\end{array}$}} & \multirow{2}{*}{\multicolumn{2}{|c|}{$\begin{array}{c}107 \\
207(65-272)\end{array}$}} & \multirow{2}{*}{\multicolumn{2}{|c|}{$\begin{array}{c}109 \\
215(65-280)\end{array}$}} \\
\hline Range & & & & & & \\
\hline
\end{tabular}

NDM, no diabetes; PDM, pregestational diabetes mellitus; GDM, gestational diabetes mellitus; WIC, Special Supplemental Nutrition Program for Women, Infants, and Children; NICU, neonatal intensive care unit.

Values are weighted, unadjusted estimates with their standard errors; $n 72755$ includes data from thirty states (AK, AR, CO, DE, GA, HI, IL, MA, MD, ME, MI, MN, MO, MS, NE, NJ, NM, NY, OH, OK, OR, PA, RI, TN, TX, UT, WA, WI, WV, WY) and New York City.

$\chi^{2} P$ values are denoted as follows: ${ }^{\star} P<0.05,{ }^{\star \star} P<0.01,{ }^{* \star *} P<0.001$.

alone did not satisfy my baby' $(22 \cdot 8 \%, 22 \cdot 2 \%$ and $14 \cdot 6 \%$, respectively) and 'My baby had difficulty latching or nursing' (22.1 \%, 22.3\% and $19.5 \%$, respectively; Table 3$)$.

To assess evidence of selection bias, the 360 women who answered 'no' to one of the diabetes questions and had data missing on the other diabetes question that were initially excluded from the analyses were added back and coded as NDM. Results did not change.

\section{Discussion}

The present population-based study demonstrated that women with PDM have the lowest breast-feeding initiation and continuation prevalence compared with women with NDM or GDM. The finding regarding lower breast-feeding initiation prevalence for women with PDM compared with NDM is supported by other studies conducted in Canada 
and Germany, where women with type 1 or insulindependent diabetes were found to have lower prevalence of breast-feeding initiation or breast-feeding at time of hospital discharge than women without diabetes ${ }^{(27,28)}$. Similarly, the finding that women with PDM have lower breast-feeding prevalence than women with GDM is also supported by others ${ }^{(27,30,46)}$. Research in Germany found an increasing trend in breast-feeding among women with PDM, although the prevalence was still lower than in the rest of the population ${ }^{(28,29)}$. In a recent study in a university hospital in Ohio, among 392 women with PDM and other chronic metabolic disorders associated with a high risk of GDM, breast-feeding prevalence was $41 \%{ }^{(18)}$, compared with the overall state prevalence of $62 \%{ }^{(47)}$.

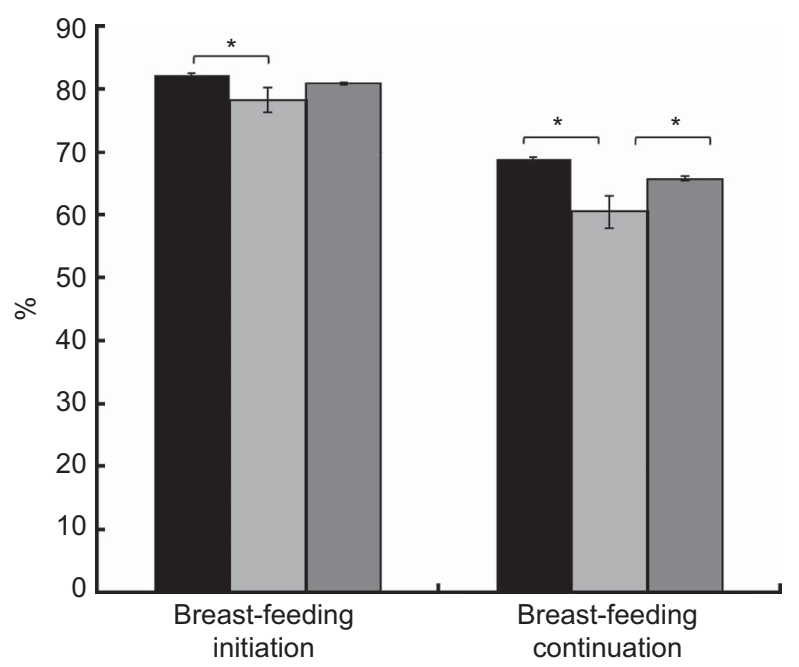

Fig. 1 Breast-feeding initiation and continuation by maternal diabetes status ( $\square$, no diabetes (NDM); $\square$, pregestational diabetes mellitus (PDM); $\square$, gestational diabetes mellitus (GDM)); Pregnancy Risk Assessment Monitoring System (PRAMS), 2009-2011. Values are weighted, unadjusted estimates with their standard errors represented by vertical bars ( $n 72755$ for initiation and $n 60381$ for continuation). *Group differences significant at $P<0.05$
Possible explanations for the discrepancy in initiation prevalence between PDM and other women may relate to higher rates of caesarean delivery, preterm delivery, infant admission to the neonatal intensive care unit, younger maternal age and higher maternal $\mathrm{BMI}^{(27,28,30,48)}$, as well as possible delayed lactogenesis II associated with metabolic issues such as glucose intolerance ${ }^{(49)}$. These factors and potential maternal-infant separation may negatively impact milk production in the first days postpartum.

The findings of our study show that women with GDM and NDM had similar breast-feeding initiation prevalence, suggesting that having diabetes diagnosed during pregnancy may not negatively affect breast-feeding initiation. A retrospective cohort study of nearly 25000 deliveries at four hospitals in Canada found lower exclusive breast-feeding prevalence among GDM women compared with NDM women, although any amount of breast-feeding by discharge was not reported ${ }^{(27)}$, thereby limiting the comparison of these two studies as the outcome measure differs.

Breast-feeding duration prevalence has been found to be lower among women with type 1 diabetes compared with NDM in international non-intervention studies ${ }^{(28,29,48)}$. A study examining breast-feeding in 102 women with type 1 diabetes in Denmark found that $68 \%$ of the women were breast-feeding either partially or exclusively at 4 months postpartum, which is lower than the overall national Danish 4-month breast-feeding prevalence of $76 \%{ }^{(50)}$. A retrospective study conducted in the UK of ninety-four women with diabetes found that breast-feeding at 4 months was inversely associated with early prenatal BMI and at 6 months was significantly predicted by higher socio-economic status $^{(30)}$. Similarly, in a case-control study in Sweden of 212 women, maternal type 1 diabetes status was not a factor in the adjusted model predicting breast-feeding at 2 months postpartum, while significant predictors were maternal education and having breast-fed at discharge ${ }^{(31)}$. The researchers explained that they excluded women with type 2 diabetes since they are rare in Sweden, as well as women with GDM since there is usually a resolution of diabetes

Table 2 Multivariable adjusted associations between breast-feeding initiation and continuation by maternal diabetes status; Pregnancy Risk Assessment Monitoring System (PRAMS), 2009-2011

\begin{tabular}{|c|c|c|c|c|c|c|c|c|c|c|c|c|}
\hline & \multicolumn{8}{|c|}{ Initiation (n 72755 ) } & \multicolumn{4}{|c|}{ Continuation (n 60381 ) } \\
\hline & \multicolumn{2}{|c|}{ Unadjusted } & \multicolumn{2}{|c|}{ Full model† } & \multicolumn{2}{|c|}{ Smokerł } & \multicolumn{2}{|c|}{ Non-smokerł } & \multicolumn{2}{|c|}{ Unadjusted } & \multicolumn{2}{|c|}{ Full model§ } \\
\hline & OR & $95 \% \mathrm{Cl}$ & OR & $95 \% \mathrm{Cl}$ & OR & $95 \% \mathrm{Cl}$ & OR & $95 \% \mathrm{Cl}$ & OR & $95 \% \mathrm{Cl}$ & OR & $95 \% \mathrm{Cl}$ \\
\hline PDM v. NDM & 0.78 & $0.62,0.98$ & 0.81 & $0.64,1.04$ & $1 \cdot 26$ & $0.83,1.93$ & 0.71 & $0.54,0.94$ & 0.69 & $0.56,0.86$ & 0.71 & $0.56,0.91$ \\
\hline GDM v. NDM & 0.92 & $0.81,1.03$ & 0.93 & $0.81,1.06$ & 1.31 & $1.03,1.69$ & 0.83 & $0.72,0.97$ & 0.87 & $0.78,0.97$ & 0.89 & $0.79,1.00$ \\
\hline GDM v. PDM & 1.17 & $0.91,1.51$ & 1.14 & $0.87,1.49$ & 1.03 & $0.64,1.66$ & 1.17 & $0.86,1.59$ & 1.25 & $0.99,1.59$ & 1.25 & $0.96,1.63$ \\
\hline
\end{tabular}

NDM, no diabetes; PDM, pregestational diabetes mellitus; GDM, gestational diabetes mellitus.

†Adjusted for maternal age, race/ethnicity, marital status, pre-pregnancy BMI, maternal education, previous live births, preterm birth, intention to become pregnant, current smoking status, participation in the Special Supplemental Nutrition Program for Women, Infants, and Children (WIC), insurance at delivery, infant admission to the neonatal intensive care unit, discussed breast-feeding with a health-care worker during any prenatal visit and type of delivery.

$\ddagger$ Adjusted for all the same variables as the full model in $\dagger$, except stratified by current smoking status.

$\S$ Adjusted for maternal age, race/ethnicity, marital status, pre-pregnancy BMI, maternal education, previous live births, preterm birth, current smoking status, participation in WIC and type of delivery. 
Table 3 Reasons for not initiating or continuing breast-feeding by maternal diabetes status; Pregnancy Risk Assessment Monitoring System (PRAMS), 2009-2011

\begin{tabular}{|c|c|c|c|}
\hline \multirow[b]{2}{*}{ Reason } & \multicolumn{3}{|c|}{$\%$} \\
\hline & $\begin{array}{c}\text { NDM } \\
(n \text { 3438) }\end{array}$ & $\begin{array}{l}\text { PDM } \\
(n 94)\end{array}$ & $\begin{array}{c}\text { GDM } \\
(n 382)\end{array}$ \\
\hline \multicolumn{4}{|c|}{ Among mothers who did not breast-feed, reasons for not initiating breast-feeding $\dagger$} \\
\hline I didn't want to breast-feed & $47 \cdot 7$ & 52.5 & $47 \cdot 1$ \\
\hline I didn't like breast-feeding & 28.7 & 35.4 & $30 \cdot 6$ \\
\hline I had other children to take care of & $20 \cdot 1$ & $18 \cdot 1$ & $28 \cdot 3$ \\
\hline I was sick or on medicine & $15 \cdot 1$ & 29.9 & $13 \cdot 8$ \\
\hline I tried but it was too hard & $15 \cdot 4$ & $14 \cdot 1$ & $16 \cdot 0$ \\
\hline I went back to work or school & 14.7 & 4.5 & $18 \cdot 4$ \\
\hline I had too many household duties & $10 \cdot 8$ & $16 \cdot 5$ & $17 \cdot 2$ \\
\hline I wanted my body back to myself & $7 \cdot 2$ & 2.5 & $4 \cdot \overline{7}$ \\
\hline I was embarrassed to breast-feed & $6 \cdot 2$ & $7 \cdot 8$ & $2 \cdot 7$ \\
\hline My baby was sick and was not able to breast-feed & $2 \cdot 1$ & 1.4 & $2 \cdot 5$ \\
\hline \multirow[t]{2}{*}{ Other } & $17 \cdot 8$ & $14 \cdot 8$ & $17 \cdot 6$ \\
\hline & $\begin{array}{c}\text { NDM } \\
(n \text { 8870) }\end{array}$ & $\begin{array}{l}\text { PDM } \\
\text { (n 221) }\end{array}$ & $\begin{array}{c}\text { GDM } \\
(n \text { 952) }\end{array}$ \\
\hline \multicolumn{4}{|c|}{ Among mothers who initiated breast-feeding, reasons for not continuing breast-feeding $\ddagger$} \\
\hline I thought I was not producing enough milk & $26 \cdot 8$ & $24 \cdot 8$ & $27 \cdot 6$ \\
\hline Breast milk alone did not satisfy my baby & $22 \cdot 2$ & 14.6 & $22 \cdot 8$ \\
\hline My baby had difficulty latching or nursing & $22 \cdot 3$ & $19 \cdot 5$ & $22 \cdot 1$ \\
\hline It was too hard, painful, or too time consuming & $16 \cdot 3$ & 8.4 & 11.9 \\
\hline I went back to work or school & 8.7 & 8.9 & 8.6 \\
\hline My nipples were sore, cracked or bleeding & $12 \cdot 9$ & 5.5 & $11 \cdot 2$ \\
\hline I had too many other household duties & $7 \cdot 0$ & $8 \cdot 7$ & $5 \cdot \overline{5}$ \\
\hline I thought my baby was not gaining enough weight & 5.6 & 3.0 & $6 \cdot 4$ \\
\hline I felt it was the right time to stop breast-feeding & $4 \cdot 1$ & 0.6 & 4.9 \\
\hline I got sick and was not able to breast-feed & 4.4 & 6.5 & $4 \cdot 6$ \\
\hline My baby was jaundiced (yellowing of the skin or whites of the eyes) & $5 \cdot 2$ & 8.3 & 4.7 \\
\hline Other & $12 \cdot 6$ & $15 \cdot 0$ & $10 \cdot 8$ \\
\hline
\end{tabular}

Values are weighted, unadjusted estimates; \% represents the proportion of mothers who checked each item; \% exceeds $100 \%$ since each was a 'check all that apply' question.

†Based on the question 'What were your reasons for not breast-feeding your new baby?' and 3914 women from eight states (GA, IL, NH, RI, TN, TX, WI, WV). łBased on the question 'What were your reasons for stopping breast-feeding?' and 10043 women from eleven states (CO, GA, HI, IL, MI, MN, NE, NM, OH, TN, UT) plus New York City.

following delivery, which is different from the increasing public health issue of diabetes among women of reproductive age in the USA. It is noteworthy that breast-feeding duration is defined in different manners by the various studies such as breast-feeding at 2, 4 or 6 months, or using maternal report of timing of cessation during the first year of life, as in our study. In general, our findings contribute novel information as our study reflects population-based data of breast-feeding initiation and 2-month duration among women with diabetes in pregnancy, offering stronger analytic power and representativeness than the international studies mentioned above.

Various health, prenatal, postpartum, lactation, sociodemographic, cultural and lifestyle factors have been found to affect breast-feeding initiation and continuation for the general postpartum population. Among women with diabetes, factors other than diabetes status may influence breast-feeding continuation including sociodemographic factors such as maternal education, socio-economic level, maternal BMI and breast-feeding by discharge ${ }^{(30,31,50)}$. In our study, the reasons for not initiating breast-feeding expressed by at least three-quarters of the study population were not wanting to breast-feed and not liking breastfeeding. These reasons suggest that more promotion of breast-feeding and education regarding the importance of breast-feeding prior to delivery, and early postpartum support and encouragement, may help motivate women to initiate breast-feeding. The reasons for not continuing breast-feeding expressed by the majority of the study population were perceived insufficient milk supply, infant not sufficiently satisfied with breast-feeding and difficulty latching or nursing. Perceived insufficient milk supply was also noted as the primary lactation-related reason for breast-feeding termination among women with diabetes in an earlier study ${ }^{(50)}$. The reasons shared by women regarding the decision to terminate breast-feeding suggest the need for health-care providers to provide continued support and guidance in addressing breast-feeding challenges during the postpartum period.

Additionally, research demonstrates a relationship among modifiable risk factors of prenatal smoking and lack of breast-feeding among women in different regions of the $\mathrm{USA}^{(51)}$. In our study, as in another recent study ${ }^{(18)}$, smoking was associated with lower breast-feeding initiation rates 
among women with diabetes. Among women who were non-smokers, PDM women had the lowest breast-feeding initiation rates compared with GDM and NDM. In contrast, among women who were smokers, those with GDM had higher breast-feeding initiation rates than NDM, which was an unexpected finding. A possible explanation is that women diagnosed with diabetes in pregnancy received comprehensive instruction and recommendations regarding healthy lifestyle changes in an effort to manage their GDM and prevent postpartum diabetes, which may have included the modifiable behaviour of smoking cessation.

The present study was limited in that it was a secondary data analysis, limiting the availability of variables relevant to the questions of interest such as the survey's definitions of diabetes and breast-feeding initiation and continuation, resulting in reduced comparability across studies due to varying definitions. Additionally, breast-feeding intention, a variable often used to anticipate differences in breastfeeding behaviour, was asked only by one state and one city, and thus could not be used in the analyses. A second limitation was that the findings may not be generalizable beyond the thirty states and one city included in the analyses; however, the study sample extended across the USA and was not limited to one region of the country. Another strength of the study was that the PRAMS survey years used in the analysis (2009-2011) were the first years to include a more explicit question to better differentiate between pre-pregnancy diabetes and gestational diabetes, and also included questions on breast-feeding initiation and continuation. To date, population-based studies in the USA do not ask women both questions within the same survey.

\section{Clinical and policy implications}

Pregnancies affected by diabetes have increased risk of adverse outcomes for the woman and her offspring. As such, it is crucial to promote health behaviours such as breast-feeding in an effort to reduce the negative risks and to afford maternal-infant health protection. Beyond prenatal diabetes screening, management and follow-up, postpartum recommendations, support and education regarding the importance and practice of breast-feeding will contribute to the prevention of additional complications associated with diabetes in pregnancy. A prenatal and postpartum breast-feeding intervention for women with type 1 diabetes in Denmark that included early postpartum pumping facilitated breast-feeding initiation and duration, so that the women's rates were comparable to those of the general Danish population ${ }^{(50)}$. That intervention study provides evidence for breast-feeding support and education delivered by trained health-care providers for women with diabetes during pregnancy ${ }^{(50)}$. Early postpartum breast-feeding support should include encouragement with early and frequent milk expression as well as reducing maternal-infant separation, thereby minimizing delayed lactogenesis II and enhancing breast milk production. It is important to provide practical assistance in overcoming challenges faced by women with diabetes in pregnancy in the early postpartum period to facilitate the transition from breast-feeding initiation to continuation and to assist women in overcoming some of the most commonly expressed reasons for not initiating or continuing breast-feeding.

Future studies on breast-feeding among women with diabetes should differentiate between GDM and PDM as their experiences with breast-feeding differ. The findings of the current study can inform breast-feeding education and promotion activities, particularly related to improving prenatal health education of women with PDM and GDM, to help meet Healthy People 2020 goals for breast-feeding initiation and continuation. Additional support of breastfeeding continuation is needed across groups to meet national goals.

\section{Acknowledgements}

Acknowledgements: The authors would like to acknowledge the PRAMS Working Group (Alabama: Izza Afgan, MPH; Alaska: Kathy Perham-Hester, MS, MPH; Arkansas: Mary McGehee, PhD; Colorado: Alyson Shupe, PhD; Delaware: George Yocher, MS; Florida: Cynthia Ulysee, MPH; Georgia: Yan Li, MD, MPH; Hawaii: Emily Roberson, MPH; Illinois: Theresa Sandidge, MA; Louisiana: Amy Zapata, MPH; Maine: Tom Patenaude, MPH; Maryland: Diana Cheng, MD; Massachusetts: Emily Lu, MPH; Michigan: Cristin Larder, MS; Minnesota: Judy Punyko, PhD, MPH; Mississippi: Brenda Hughes, MPPA; Missouri: Venkata Garikapaty, MSc, MS, PhD, MPH; Montana: JoAnn Dotson; Nebraska: Brenda Coufal; New Jersey: Lakota Kruse, MD; New Mexico: Eirian Coronado, MPH; New York State: Anne Radigan-Garcia; New York City: Candace Mulready-Ward, MPH; North Carolina: Kathleen Jones-Vessey, MS; North Dakota: Sandra Anseth; Ohio: Connie Geidenberger, PhD; Oklahoma: Alicia Lincoln, MSW, MSPH; Oregon: Kenneth Rosenberg, MD, MPH; Pennsylvania: Tony Norwood; Rhode Island: Sam Viner-Brown, PhD; South Carolina: Mike Smith, MSPH; Texas: Rochelle Kingsley, MPH; Tennessee: David Law, PhD; Utah: Laurie Baksh; Vermont: Peggy Brozicevic; Virginia: Marilyn Wenner; Washington: Linda Lohdefinck; West Virginia: Melissa Baker, MA; Wisconsin: Katherine Kvale, PhD; Wyoming: Angi Crotsenberg); Centers for Disease Control and Prevention PRAMS Team, Applied Sciences Branch, Division of Reproductive Health. Financial support: This research received no specific grant from any funding agency in the public, commercial or not-for-profit sectors. Conflict of interest: None. Authorship: R.O.-F. conceived the research questions, drafted the manuscript and supervised the analyses. I.C. drafted the manuscript. A.B. completed the analyses. All authors reviewed and approved the final version of the manuscript prior to submission. Ethics of 
buman subject participation: Nationwide Children's Hospital's Institutional Review Board deemed this study as non-human subjects research.

\section{References}

1. Coustan DR, Lowe LP, Metzger BE et al. (2010) The Hyperglycemia and Adverse Pregnancy Outcome (HAPO) study: paving the way for new diagnostic criteria for gestational diabetes mellitus. Am J Obstet Gynecol 202, 654. e1-e6.

2. American Diabetes Association (2012) Diagnosis and classification of diabetes mellitus. Diab Care 35, Suppl. 1, S64-S71.

3. Dabelea D, Snell-Bergeon JK, Hartsfield CL et al. (2005) Increasing prevalence of gestational diabetes mellitus (GDM) over time and by birth cohort: Kaiser Permanente of Colorado GDM Screening Program. Diabetes Care 28, 579-584.

4. Getahun D, Nath C, Ananth CV et al. (2008) Gestational diabetes in the United States: temporal trends 1989 through 2004. Am J Obstet Gynecol 198, 525.e1-e5.

5. Hunt KJ \& Schuller KL (2007) The increasing prevalence of diabetes in pregnancy. Obstet Gynecol Clin North Am 34, 173-199.

6. Albrecht SS, Kuklina EV, Bansil P et al. (2010) Diabetes trends among delivery hospitalizations in the US, 1994-2004. Diabetes Care 33, 768-773.

7. Hillier TA, Pedula KL, Schmidt MM et al. (2007) Childhood obesity and metabolic imprinting: the ongoing effects of maternal hyperglycemia. Diabetes Care 30, 2287-2292.

8. Metzger BE (2007) Long-term outcomes in mothers diagnosed with gestational diabetes mellitus and their offspring. Clin Obstet Gynecol 50, 972-979.

9. Clausen TD, Mathiesen ER, Hansen T et al. (2008) High prevalence of type 2 diabetes and pre-diabetes in adult offspring of women with gestational diabetes mellitus or type 1 diabetes: the role of intrauterine hyperglycemia. Diabetes Care 31, 340-346.

10. Boerschmann H, Pfluger M, Henneberger L et al. (2010) Prevalence and predictors of overweight and insulin resistance in offspring of mothers with gestational diabetes mellitus. Diabetes Care 33, 1845-1849.

11. Agrawal RK, Lui K \& Gupta JM (2000) Neonatal hypoglycaemia in infants of diabetic mothers. J Pediatr Child Health 36, 354-356.

12. Maayan-Metzger A, Lubin D \& Kuint J (2009) Hypoglycemia rates in the first days of life among term infants born to diabetic mothers. Neonatology 96, 80-85.

13. Fadl HE, Ostlund IK, Magnuson AF et al. (2010) Maternal and neonatal outcomes and time trends of gestational diabetes mellitus in Sweden from 1991 to 2003. Diabet Med 27, 436-441.

14. Weindling AM (2009) Offspring of diabetic pregnancy: short-term outcomes. Semin Fetal Neonatal Med 14, 111-118.

15. Labbok MH, Clark D \& Goldman AS (2004) Breastfeeding: maintaining an irreplaceable immunological resource. Nat Rev Immunol 4, 565-572.

16. Patelarou E, Girvalaki C, Brokalaki H et al. (2012) Current evidence on the associations of breastfeeding, infant formula, and cow's milk introduction with type 1 diabetes mellitus: a systematic review. Nutr Rev 70, 509-519.

17. Owen CG, Martin RM, Whincup PH et al. (2006) Does breastfeeding influence risk of type 2 diabetes in later life? A quantitative analysis of published evidence. Am J Clin Nutr 84, 1043-1054.
18. Cordero L, Thung S, Landon MB et al. (2014) Breast-feeding initiation in women with pregestational diabetes mellitus. Clin Pediatr (Phila) 53, 18-25.

19. Chertok IR, Raz I, Shoham I et al. (2009) Effects of early breastfeeding on neonatal glucose levels of term infants born to women with gestational diabetes. J Hum Nutr Diet 22, 166-169.

20. Schwarz EB, Brown JS, Creasman JM et al. (2010) Lactation and maternal risk of type 2 diabetes: a populationbased study. Am J Med 123, 863.e1-e6.

21. Stuebe AM, Rich-Edwards JW, Willett WC et al. (2005) Duration of lactation and incidence of type 2 diabetes. JAMA 294, 2601-2610.

22. O'Reilly MW, Avalos G, Dennedy MC et al. (2011) Atlantic DIP: high prevalence of abnormal glucose tolerance post partum is reduced by breast-feeding in women with prior gestational diabetes mellitus. Eur J Endocrinol 165, 953-959.

23. Gingras V, Paradis AM, Tchernof A et al. (2012) Relationship between the adoption of preventive practices and the metabolic profile of women with prior gestational diabetes mellitus. Appl Physiol Nutr Metab 37, 1232-1238.

24. Gunderson EP, Hedderson MM, Chiang V et al. (2012) Lactation intensity and postpartum maternal glucose tolerance and insulin resistance in women with recent GDM: the SWIFT cohort. Diabetes Care 35, 50-56.

25. Ziegler AG, Wallner M, Kaiser I et al. (2012) Long-term protective effect of lactation on the development of type 2 diabetes in women with recent gestational diabetes mellitus. Diabetes 61, 3167-3171.

26. Chouinard-Castonguay S, Weisnagel SJ, Tchernof A et al. (2013) Relationship between lactation duration and insulin and glucose response among women with prior gestational diabetes. Eur J Endocrinol 168, 515-523.

27. Finkelstein SA, Keely E, Feig DS et al. (2013) Breastfeeding in women with diabetes: lower rates despite greater rewards. A population-based study. Diabet Med 30, 1094-1101.

28. Hummel S, Winkler C, Schoen S et al. (2007) Breastfeeding habits in families with type 1 diabetes. Diabet Med $\mathbf{2 4}$, 671-676.

29. Schoen S, Sichert-Hellert W, Hummel S et al. (2008) Breastfeeding duration in families with type 1 diabetes compared to non-affected families: results from BABYDIAB and DONALD studies in Germany. Breastfeed Med 3, 171-175.

30. Soltani H \& Arden M (2009) Factors associated with breastfeeding up to 6 months postpartum in mothers with diabetes. J Obstet Gynecol Neonatal Nurs 38, 586-594.

31. Sparud-Lundin C, Wennergren M, Elfvin A et al. (2011) Breastfeeding in women with type 1 diabetes: exploration of predictive factors. Diabetes Care 34, 296-301.

32. Soltani H, Dickinson FM, Kalk J et al. (2008) Breast feeding practices and views among diabetic women: a retrospective cohort study. Midwifery 24, 471-479.

33. Neubauer SH, Ferris AM, Chase CG et al. (1993) Delayed lactogenesis in women with insulin-dependent diabetes mellitus. Am J Clin Nutr 58, 54-60.

34. Taylor JS, Kacmar JE, Nothnagle M et al. (2005) A systematic review of the literature associating breastfeeding with type 2 diabetes and gestational diabetes. J Am Coll Nutr 24, 320-326.

35. Hurst NM (2007) Recognizing and treating delayed or failed lactogenesis II. J Midwifery Womens Health 52, 588-594.

36. Trout KK, Averbuch T \& Barowski M (2011) Promoting breastfeeding among obese women and women with gestational diabetes mellitus. Curr Diab Rep 11, 7-12.

37. Gatti L (2008) Maternal perceptions of insufficient milk supply in breastfeeding. J Nurs Scholarsh 40, 355-363.

38. Brownell E, Howard CR, Lawrence RA et al. (2012) Delayed onset lactogenesis II predicts the cessation of any or exclusive breastfeeding. J Pediatr 161, 608-614. 
39. DaMota K, Banuelos J, Goldbronn J et al. (2012) Maternal request for in-hospital supplementation of healthy breastfed infants among low-income women. J Hum Lact 28, 476-482.

40. Centers for Disease Ccontrol and Prevention (2012) PRAMS model surveillance protocol phase VI. http://www.cdc.gov/ prams (accessed January 2014).

41. Dillman DA (2000) Mail and Internet Surveys: The Tailored Design Method, 2nd ed. New York: Wiley.

42. Gilbert BC, Shulman HB, Fischer LA et al. (1999) The Pregnancy Risk Assessment Monitoring System (PRAMS): methods and 1996 response rates from 11 states. Matern Child Health J 3, 199-209.

43. Shulman HB, Gilbert BC \& Lansky A (2006) The Pregnancy Risk Assessment Monitoring System (PRAMS): current methods and evaluation of 2001 response rates. Public Health Rep 121, 74-83.

44. Hosler AS, Nayak SG \& Radigan AM (2010) Agreement between self-report and birth certificate for gestational diabetes mellitus: New York State PRAMS. Matern Child Health J 14, 786-789.

45. Kotelchuck M (1994) An evaluation of the Kessner Adequacy of Prenatal Care Index and a proposed Adequacy of Prenatal Care Utilization Index. Am J Public Health 84, 1414-1420.

46. Simmons D, Conroy C \& Thompson CF (2004) In-hospital breast feeding rates among women with gestational diabetes and pregestational type 2 diabetes in South Auckland. Diabet Med 22, 177-181.

47. Centers for Disease Ccontrol and Prevention (2012) Breastfeeding Report Card. http://www.cdc.gov/breastfeeding/ data/reportcard/reportcard2012.htm (accessed April 2014)

48. Sorkio S, Cuthbertson D, Barlund S et al. (2010) Breastfeeding patterns of mothers with type 1 diabetes: results from an infant feeding trial. Diabetes Metab Res Rev 26, 206-211.

49. Nommsen-Rivers LA, Dolan LM \& Huang B (2012) Timing of stage II lactogenesis is predicted by antenatal metabolic health in a cohort of primiparas. Breastfeed Med 7, 43-49.

50. Stage E, Norgard H, Damm P et al. (2006) Long-term breastfeeding in women with type 1 diabetes. Diabetes Care 29, 771-774.

51. Amir LH \& Donath SM (2003) Does maternal smoking have a negative physiological effect on breastfeeding? The epidemiological evidence. Breastfeed Rev 11, 19-29. 